\title{
TETRACICLINAS: UN MODELO DE RESISTENCIA ANTIMICROBIANA
}

TETRACYCLINES: A MODEL OF ANTIMICROBIAL RESISTANCE

\author{
MARÍA ANTONIETA JARA O. MV. MSC. ${ }^{1}$
}

\begin{abstract}
Tetracyclines are a group of broad-spectrum antibiotics whose general usefulness has been reduced with the onset of bacterial resistance. Tetracycline resistance is the most frequent bacterial antibiotic resistance found in nature and is mostly acquired by horizontal gene transfer. Nowadays, 39 acquired tetracycline determinants are known for bacteria. Nucleic acid-based detection systems offer rapid and sensitive methods to detect the presence of resistance genes and play a critical role in the elucidation of resistance mechanisms. Resistance to the antibiotic is conferred by 1 or more of the 39 currently described tet genes, which encode one of three mechanisms of resistance: use of an energy dependent efflux of tetracycline, altering the ribosome to prevent effective binding of the tetracycline, and producing tetracycline-inactivating enzymes. Efflux mechanisms appear to be more abundant among gram-negative microorganisms, while ribosomal protection mechanisms are more common among gram-positive organisms. Generally speaking, the rapid spread of tetracycline resistance among bacteria is due to the localization of tet genes on plasmids, transposons, and integrons.

Molecular analysis of bacterial resistance has yielded a wealth of information during the last decade. With the aid of molecular amplification techniques, great progress has been made in our knowledge of the distribution and spread of resistance markers among the species.
\end{abstract}

KEY WORDS: Tetracycline, tet genes, antimicrobial resistance.

Palabras ClaVe: Tetraciclina, genes tet, resistencia antimicrobiana.

\section{INTRODUCCIÓN}

Las tetraciclinas son antimicrobianos de amplio espectro, con actividad contra una gran gama de bacterias gram-positivas y gram-negativas, aerobios y anaerobios, microorganismos atípicos como Chlamydia sp, Rickettsia sp, Micoplasma sp, Borrelia sp, Treponema pallidum, Helicobacter pylori, Plasmodium sp y algunas micobacterias. Pertenecen a un grupo de antibióticos con una estructura química tetracíclica básica y actividad biológica común, formadas por la fusión de cuatro anillos bencénicos con diversos sustituyentes (Figura 1). En el año 1948 aparece el primero de estos antibióticos, la clortetraciclina, a partir de un cultivo de Streptomyces aureofaciens; dos años más tarde se aísla la oxitetraciclina de $S$.

1 Unidad de Microbiología. Facultad de Ciencias Veterinarias y Pecuarias. Universidad de Chile. Santa Rosa 11735. La Granja. rimosus y en los años siguientes se descubren la tetraciclina y la demetilclortetraciclina. A partir de ese momento y con el avance de la bioquímica, surgen las tetraciclinas semisintéticas: minociclina, metaciclina, doxiciclina y las últimas en ser sintetizados son las glicilciclinas, que surgen modificando la posición 9 del anillo tetracíclico, con lo que aumenta su actividad antimicrobiana, resultando sensibles un gran número de bacterias resistentes a otras tetraciclinas (Chopra y Roberts, 2001; Golstein y col., 1994). La tigilciclina es el prototipo de este nuevo grupo, y deriva de la minociclina. La aparición de estas glicilciclinas ha hecho que puedan clasificarse en "generaciones", según el orden de su descubrimiento (Cuadro 1).

\section{MODO DE ACCIÓN}

Las tetraciclinas son antibióticos bacteriostáticos que inhiben, en forma reversible, la síntesis de proteínas 
FIGURA 1

ESTRUCTURAS QUÍMICAS DE TETRACICLINAS

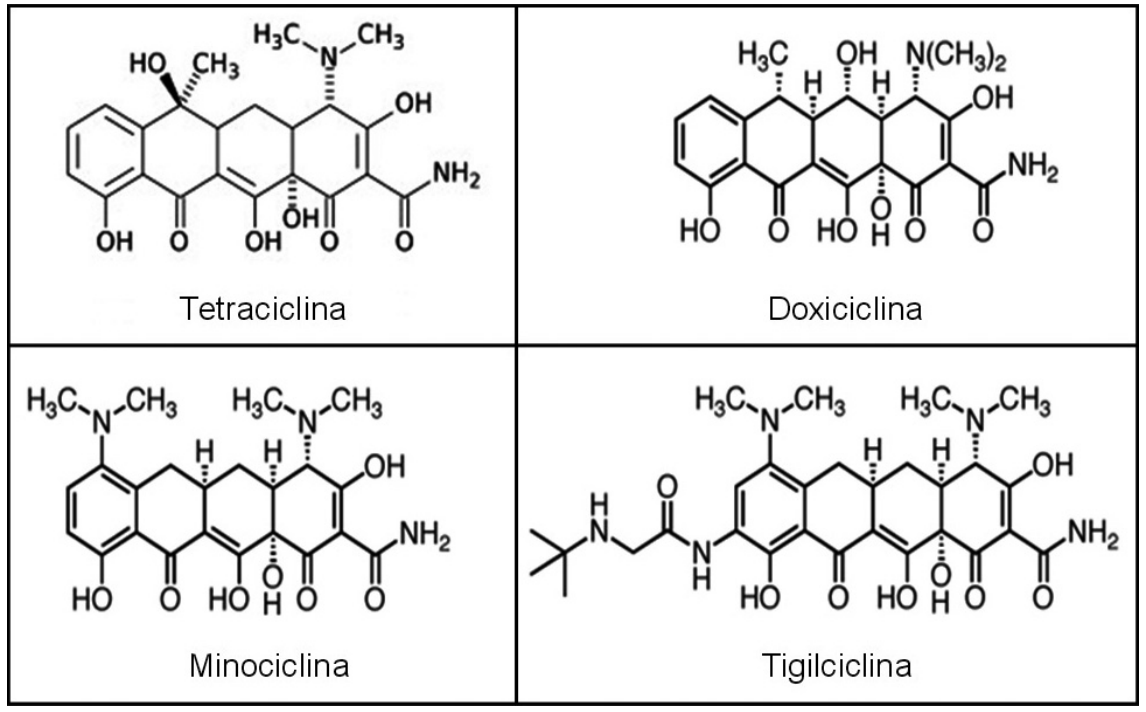

impidiendo la unión del aminoacil-tRNA al sitio A del ribosoma bacteriano, uniéndose directamente a la proteína S7 de la subnidad 30S (Goldman y col., 1983). De ahí, entonces, que para interactuar con su sitio blanco necesitan atravesar uno o dos sistemas de membrana, dependiendo de si el microorganismo es gram-positivo o gram-negativo. Atraviesan la pared celular por difusión pasiva y la membrana citoplasmática por un proceso dependiente de energía (Yamaguchi y col., 1991). En el caso de las bacterias entéricas gram-negativas, atraviesan la membrana externa a través de las porinas $\mathrm{OmpF}$ y OmpC mediante difusión pasiva y por un proceso de energía dependiente la membrana citoplasmática (Chopra y Roberts, 2001; Michalova y col., 2004).

\section{Resistencia}

Hasta mediados de la década del 50, la mayoría de las bacterias comensales y patógenas eran susceptibles a las tetraciclinas. Así lo demuestra un trabajo realizado con 433 cepas de diferentes enterobacterias recolectadas entre 1917 y 1954 donde la resistencia a este antibiótico era sólo un 2\% (Hughes y Datta, 1983). Estudios en bacterias ambientales, representativas de poblaciones existentes antes del uso masivo de esta droga por el hombre (Dancer y col., 1997), también apoyan la opinión que la emergencia de resistencia es un hecho relativamente reciente como consecuencia de una serie de factores como el uso y mal uso en medicina humana, la introducción en la clínica veterinaria, el uso como promotores de crecimiento en los animales de producción y la aplicación en la agricultura. La resistencia ha surgido como consecuencia de la adquisición de genes tet (tetraciclina) y/o genes otr (oxitetraciclina) por parte de las bacterias comensales y patógenas (Chopra y Roberts, 2001).

En la actualidad se sabe que la resistencia a tetraciclina que adquiere una bacteria está mediada por

\section{CUADRO 1}

CLASIFICACIÓN DE LAS TETRACICLINAS SEGÚN DESCUBRIMIENTO O SÍNTESIS

\begin{tabular}{l|l}
\hline \multirow{2}{*}{ Primera generación (1948-1963) } & Clortetraciclina \\
\cline { 2 - 2 } & Oxitetraciclina \\
\cline { 2 - 2 } & Tetraciclina \\
\cline { 2 - 2 } Segunda generación (1965-1972) & Demetilclortetraciclina \\
\cline { 2 - 2 } & Metaciclina \\
\cline { 2 - 2 } & Doxiciclina \\
\hline Tercera generación (1993) & Glicilciclina \\
\hline
\end{tabular}


tres mecanismos: eflujo activo, protección ribosomal e inactivación enzimática. Los dos primeros mecanismos están extensamente distribuidos tanto entre microorganismos gram-negativos como gram-positivos, mientras el tercero ha sido descrito sólo en algunos géneros bacterianos (Chopra y Roberts, 2001; Roberts., 2005; Ross y col., 1998; Yang y col., 2004).

Desde que se conoció el primer informe de resistencia transferible a tetraciclina, en Shigella dysenteriae en el año 1960 (Akiba y col., 1960), se han descrito a lo menos 24 genes que codifican para bombas de eflujo y 11 genes que codifican para proteínas de protección ribosomal (Roberts, 1996; Roberts, 2005). La protección ribosomal, como mecanismo de resistencia a tetraciclina fue descrito en estreptococos (Burdett, 1986) y los mediadores involucrados en este mecanismo de resistencia son proteínas (TetM,TetO, TetQ, y TetS) que tienen la capacidad de bloquear la unión de la tetraciclina a la subunidad $30 \mathrm{~S}$ del ribosoma (Chopra y Roberts, 2001).

\section{Nomenclatura de los determinantes de resistencia}

Los genes tet se designan con letras, por ejemplo, tet(M). Sin embargo, los descritos hasta las fecha sobrepasan el alfabeto, por lo cual los nuevos genes se designan con números: tet(31) (Levy y col., 1999). Actualmente se reconocen 39 genes que confieren resistencia a las tetraciclinas. Así como ha aumentado el número de genes descritos, han aumentado también los géneros bacterianos que los portan (Roberts, 2005). Recientemente y para evitar la sobreposición de nombres para un mismo determinante -descubierto por laboratorios distintos- se ha propuesto al grupo de investigadores liderados por S. Levy como coordinadores de tales determinaciones, sugiriendo un $80 \%$ o menos de identidad aminoacídica para ser denominado como nuevo determinante (Levy y col., 1999).

\section{Mecanismos}

Se han descrito tres mecanismos principales de resistencia a tetraciclinas (Roberts, 2005).

- Eflujo activo.

- Protección ribosomal.

- Inactivación enzimática.

Se describen 39 genes tet y otr que incluyen 25 genes que codifican proteínas de eflujo activo, 11 genes que codifican proteínas de protección ribosomal y 3 que codifican una enzima inactivante, además de un gen con un mecanismo de acción desconocido.

\section{Eflujo activo}

Todos los genes tet de eflujo codifican proteínas Tet asociadas a membranas que expulsan tetraciclinas de la célula, disminuyendo la concentración intracelular de la droga, protegiendo de esta manera los ribosomas. Las proteínas de eflujo son las proteínas Tet mejor estudiadas. Los genes tet se encuentran tanto en bacterias gram-positivas como en gram-negativas. El eflujo de tetraciclinas está mediado por bombas de eflujo dependientes de energía. Sus proteínas son codificadas por los genes: $\operatorname{tet}(\mathrm{A}), \operatorname{tet}(\mathrm{B}), \operatorname{tet}(\mathrm{C})$, $\operatorname{tet}(\mathrm{D}), \operatorname{tet}(\mathrm{E}), \operatorname{tet}(\mathrm{G}), \operatorname{tet}(\mathrm{H}), \operatorname{tet}(\mathrm{I}), \operatorname{tet}(\mathrm{J}), \operatorname{tet}(\mathrm{K}), \operatorname{tet}(\mathrm{L})$, $\operatorname{tet}(\mathrm{Y}), \operatorname{tet}(30), \operatorname{tet}(31), \operatorname{tet}(34), \operatorname{tet}(35) \mathrm{y} \operatorname{tet}(39)$, en las gram-negativas y por tet $(\mathrm{K}), \operatorname{tet}(\mathrm{L}), \operatorname{tet} A(\mathrm{P}), \operatorname{tet}(\mathrm{V})$, $\operatorname{tet}(\mathrm{Z}), \operatorname{tet}(33), \operatorname{tcr} 3, \operatorname{otr}(\mathrm{B}), \operatorname{otr}(\mathrm{C})$ en las bacterias gram-positivas (Michalova y col., 2004).

Últimamente se ha sido descrito un nuevo determinante de resistencia denominado Tet39 en cepas de Acinetobacter no relacionadas. Este determinante -localizado en plasmidios transferibles- se denominó tetA (39) y su mecanismo de acción sería probablemente a través de eflujo activo (Agerso y Guardabassi, 2005).

\section{Protección ribosomal}

Es el segundo mecanismo más importante de resistencia a las tetraciclinas y fue descrito por primera vez en estreptococos (Burdett, 1986). Existen 11 genes tet que codifican proteínas de protección ribosomal, siendo las más estudiadas las proteínas Tet(O) y Tet(M) (Burdett, 1991; Taylor y Chau, 1996). En años recientes se ha desarrollado un modelo para la interacción de estas proteínas con el ribosoma bacteriano (Connell y col, 2003). El modelo se basa en la hipótesis de que, en condiciones normales, los ribosomas tienen una configuración estándar y funcionan normalmente, lo que se altera al penetrar el antibiótico. La unión al ribosoma produce un cambio conformacional que impide la elongación de la cadena polipéptica, deteniéndose la síntesis de proteínas.

Las proteínas de protección ribosomal están codificadas por los genes $\operatorname{tet}(\mathrm{O}), \operatorname{tet}(\mathrm{M}), \operatorname{tet}(\mathrm{S}), \operatorname{tet}(\mathrm{Q})$, $\operatorname{tet}(\mathrm{T}), \operatorname{tet}(\mathrm{W}), \operatorname{tet} B(\mathrm{P}), \operatorname{otr}(\mathrm{A}), \operatorname{tet}, \operatorname{tet}(32) \mathrm{y} \operatorname{tet}(36)$.

\section{Inactivación enzimática}

Este mecanismo de resistencia a tetraciclina comprende sólo tres genes: tet(X) tet (34) y tet(37), siendo el primero de ellos el gen tet(X) encontrado en dos transposones de Bacteroides, bacteria anaeróbica que, paradójicamente, codifica una oxidoreductasa (Speer $y$ col., 1991). El gen tet(34) presente en un Vibrio aislado 
del contenido intestinal de un pez marino (Nonaka y Suzuki, 2002) y el tet(37) presente en la microflora oral del hombre (Díaz-Torres y col., 2003).

\section{Mecanismo de resistencia desconocido}

El gen $\operatorname{tet}(\mathrm{U})$ localizado en un plasmidio de $E n$ terococcus faecium, codifica la proteína TetU que es más pequeña que las proteínas responsables de mecanismos de eflujo o de protección ribosomal y confiere resistencia a bajos niveles de tetraciclina. No está claro cómo actúa y de ahí su denominación de "Mecanismo de resistencia desconocido". Otro gen incluido en este grupo es el gen $\operatorname{Otr}(\mathrm{C})$, descrito en Streptomyces. Se especula que no codifica ni para proteínas de protección ribosomal ni para eflujo. No se ha determinado si su mecanismo es por inactivación enzimática (Chopra y Roberts, 2001).

\section{DISTRIBUCIÓN Y MOVILIDAD DE LOS GENES tet}

Los genes tet se encuentran en una variedad de bacterias aisladas del hombre, animales y del medio ambiente. La mayoría de estos determinantes se ubican en el cromosoma o en plasmidios conjugativos o no conjugativos. Muchos genes tet están asociados con transposones conjugativos o no conjugativos y luego pueden localizarse en plasmidios o en el cromosoma. (Roberts, 1994). La naturaleza móvil de muchos genes de resistencia a la tetraciclina puede explicar en parte su amplia distribución entre diferentes especies bacterianas. (Roberts, 1996). De todos los genes tet de protección ribosomal estudiados, el gen tet $\mathrm{M}$ posee la mayor distribución, probablemente por su asociación con transposones de alta tasa de conjugación, como Tn916 en Streptococcus spp. y Tn1545 en Enterococcus spp. (Clewell y col., 1995). Estos elementos han sido identificados en más de 50 géneros bacterianos diferentes, tanto gram-negativos como gram-positivos y han jugado un papel principal en la diseminación de determinantes de resistencia de antibiótico entre y a través de géneros (Chopra y Roberts. 2001; Clewell y col., 1995).

\section{Determinantes de eflujo activo de bacterias gram-negativas}

Los genes de eflujo de las bacterias gram-negativas están ampliamente distribuidos y generalmente están asociados con plasmidios que pertenecen a diferentes grupos de incompatibilidad (Mendez y col., 1980;
Jones y col., 1992; Roberts, 1996). Estos genes, frecuentemente, son parte de transposones, capaces de cambiar su localización dentro de la célula y adquirir una movilidad aumentada insertándose en un plasmidio conjugativo.

Los plasmidios de las bacterias gram-negativas a menudo llevan varios determinantes de resistencia a antibióticos (además de determinantes de resistencia a metales pesados y/o genes que codifican toxinas) confiriendo así el fenotipo de multidroga resistente. Por estudios de conjugación de estos plasmidios se ha observado que los genes de resistencia se transmiten como un cluster. Se ha demostrado que están localizados en el integron (Tosini $y$ col., 1998). Los integrones son elementos genéticos capaces de capturar y diseminar genes de resistencia, confiriendo así resistencia a antibióticos, especialmente en bacterias gram-negativas.

Se piensa que la conjugación es el mecanismo más importante de diseminación de la resistencia entre las bacterias y puede realizarse vía plasmidios conjugativos o transposones conjugativos. Los genes $t \operatorname{tet}(\mathrm{A}), \operatorname{tet}(\mathrm{B}), \operatorname{tet}(\mathrm{C}), \operatorname{tet}(\mathrm{D}), \operatorname{tet}(\mathrm{E}), \operatorname{tet}(\mathrm{G}), \operatorname{tet}(\mathrm{H})$, $\operatorname{tet}(\mathrm{I}), \operatorname{tet}(\mathrm{Y}), \operatorname{tet}(30)$ y $\operatorname{tet}(31)$ se han encontrado exclusivamente en géneros gram-negativos (Roberts, 1996). La mayoría de estos géneros corresponden a entéricos facultativos.

\section{Determinantes de eflujo activo de bacterias gram-positivas}

Se describen los genes tet $(\mathrm{K}), \operatorname{tet}(\mathrm{L}), \operatorname{tet}(\mathrm{A}) \mathrm{P}, \operatorname{tet}(\mathrm{V})$, tet( (Z), tet(33), tcr3 y otr(B), asociados a plasmidios. El plasmidio pT181 de Staphylococcus aureus es considerado el prototipo de plasmidio tet $(\mathrm{K})$. El gen $\operatorname{tet}(\mathrm{L})$ se encuentra comúnmente en plasmidios de Bacillus y es el segundo gen de resistencia a la tetraciclina más prevalente en estreptococos y enterococos (Michalova y col., 2004).

\section{Determinantes de protección ribosomal}

Se describen ocho genes tet: tet $(\mathrm{M}), \operatorname{tet}(\mathrm{O}), \operatorname{tet}(\mathrm{S})$, $\operatorname{tet}(\mathrm{W}), \operatorname{tet}(\mathrm{Q}), \operatorname{tet}(\mathrm{T}), \operatorname{tet} B(\mathrm{P})$ y tet; y un gen otr, otr(A) que codifican para mecanismos de protección ribosomal de resistencia a tetraciclina. Generalmente, están asociados con transposones conjugativos, con preferencia por el cromosoma (Roberts, 1997). Se consideran de origen gram-positivo, sin embargo, a menudo se encuentran en una variedad de especies gram-negativas (Roberts, 1996)

El gen tet( $(\mathrm{M})$ es el más ampliamente distribuido en las bacterias gram-positivas (Roberts, 1996). Se 
identificó por primera vez en Streptococcus spp. (Burdett, 1986) y posteriormente se ha descrito en una gran cantidad de bacterias tanto gram-positivas como gram-negativas, como también en micoplasmas y ureaplasmas (Roberts, 1994). Frecuentemente está asociado con transposones conjugativos de la familia Tn916-Tn1545 los que portan, además, genes de resistencia a otros antibióticos (Clewell y col., 1995; Roberts, 1996).

El gen tet $(\mathrm{O})$ es móvil sólo cuando se localiza en plasmidios conjugativos y normalmente no está asociado con transposones conjugativos (Roberts y col., 1991). Originalmente se describió en Campylobacter jejuni (Taylor y col., 1987) y en Campylobacter coli (Sougakoff $y$ col., 1987), pero se ha encontrado, además, en estreptococos donde de ubica tanto a nivel cromosomal y plasmidial (Brown y Roberts, 1991).

El gen tet(Q), identificado en Bacteroides spp., se expresa también en especies gram-positivas y gram-negativas. Está asociado con transposones conjugativos grandes, los cuales a menudo poseen genes de resistencia a la eritromicina $\operatorname{erm}(\mathrm{F})$ (Chung y col., 1999).

El gen $\operatorname{tet}(\mathrm{P})$ está en un plasmidio conjugativo de Clostridium perfringens y consiste en dos genes sobrepuestos: tet $A(\mathrm{P})$ que codifica una proteína de eflujo y el tet $B(\mathrm{P})$ que codifica una proteína de protección ribosomal. El gen tet $A(\mathrm{P})$ puede encontrarse solo, no así el gen tetB(P) (Lyras y Rood, 1996). El gen $\operatorname{tet}(\mathrm{S})$, originalmente relacionado a un plasmidio de Listeria monocytogenes (Charpentier y col., 1999), se ha encontrado también en el cromosoma de Enterococcus faecalis (Charpentier y col., 1994) y en un plasmidio conjugativo de Lactococcus spp. (Perreten y col., 1997).

El gen tet $(\mathrm{T})$ descrito en Streptococcus pyogenes A498 tiene localización cromosomal y la proteína Tet(T) está estrechamente relacionada a la proteína Tet(Q) con un $49 \%$ de homología en la secuencia de aminoácidos (Clermont y col., 1997).

El gen tet $(\mathrm{W})$, localizado en un plasmidio conjugativo, descrito en Butyrivibrio fibrisolvens aislado del rumen de los bovinos, se ha encontrado también en bacterias aisladas de heces humanas y en bacterias de la cavidad oral del hombre (Scott y col., 1997; Villedieu y col., 2003).

El gen $\operatorname{otr}(\mathrm{A})$, originalmente descrito en el cromosoma de Streptomyces rimosus productor de oxitetraciclina (Ohnuki y col., 1985), se ha encontrado posteriormente en Mycobacterium spp. y en otros Streptomyces (Pang y col., 1994).

\section{DETECCIÓN DE GENES tet EN MEDICINA VETERINARIA}

De un modo similar a lo que ocurre en Medicina Humana, se han descrito distintos genes tet en bacterias aisladas de animales de compañía, de producción bovina, ovina, porcina y acuícola, como también de bacterias del rumen y desde hace poco en bacterias nosocomiales ambientales en el Hospital Veterinario de la Facultad de Ciencias Veterinarias y Pecuarias de la Universidad de Chile.

Así, Kim y col. (2005), al intentar la detección de algunos genes tet (K, L, M y O) en Staphylococcus intermedius resistentes a tetraciclinas y cloramfenicol aislado de casos de pioderma en perros, en el $100 \%$ de las cepas detectaron uno o dos genes tet, en el $97 \%$ de las cepas resistentes a tetraciclinas detectaron tet $(\mathrm{M}) \mathrm{y}$, por otra parte, $\operatorname{tet}(\mathrm{O})$ no fue detectado. Anteriormente, en Japón ya se había descrito la detección de tet(M) en Erysipelothrix rhusiopathiae resistentes a tetraciclina aislada de cerdos con erisipela porcina (Yamamoto y col., 2001). Otro informe, señala la primera detección de tet(L) en Mannheimia y Pasteurella, microorganismos gram-negativos, aislados desde hisopados nasales de bovinos, sugiriendo así transferencia desde organismos gram-positivos (Kehrenberg $y$ col., 2005). Recientemente, se ha detectado tet( $(\mathrm{O})$ en Campylobacter jejuni asociado a un brote de aborto ovino en EE.UU., ocasión en que el 100\% de las cepas aisladas fueron resistentes a oxitetraciclinas, antimicrobiano de elección hasta ese momento (Sahin y col., 2008). En el sector acuícola, en Chile, se realizó un estudio en 25 bacterias gram-negativas distintas y resistentes a tetraciclinas aisladas desde salmones de distintas pisciculturas, encontrándose que de un panel de 22 genes tet en estudio, en 15 de ellas se detectaron los genes tet(A), tet(B), tet(34), $\operatorname{tet}(\mathrm{H}), \operatorname{tet}(\mathrm{E}), \operatorname{tet}(35)$ y tet $(\mathrm{L}), y$ los autores sugieren la existencia de genes tet no descritos aún (Miranda y col., 2003).

Finalmente, en bacterias ambientales gram-positivas descritas como nosocomiales resistentes a tetraciclinas (enterococos y estafilococos) aisladas desde el Hospital Veterinario de la Universidad de Chile, se han detectado los genes: $\operatorname{tet}(\mathrm{K}), \operatorname{tet}(\mathrm{M}) \mathrm{y}$ tet $(\mathrm{O})$, De igual forma, en bacterias gram-negativas resistentes a tetraciclinas (enterobacterias y bacilos no fermentadores) se detectaron los genes tet(A), tet $(\mathrm{B})$ y $\operatorname{tet}(\mathrm{O})$ (datos aún no publicados). 


\section{COMENTARIO FINAL}

El uso prolongado de las tetraciclinas en la terapia de enfermedades infecciosas en nuestros animales, como también el empleo en dosis subterapéuticas como profilaxis o como promotores del crecimiento adicionado en el alimento, sin duda han ejercido una permanente presión de selección sobre la flora bacteriana y con ello un riesgo muy importante para la presentación del fenómeno de resistencia. A la fecha, son numerosos los determinantes de resistencia descritos, como también numerosos son los géneros bacterianos donde se han detectado. A pesar de la enorme cantidad de trabajos publicados en las últimas décadas sobre la resistencia a los antimicrobianos, en particular a las tetraciclinas, aún permanecen aspectos no conocidos completamente sobre los mecanismos con que los microorganismos enfrentan la intervención del hombre en su biología y evolución. La biología molecular representa una herramienta clave en las investigaciones que permiten un mejor conocimiento de las "estrategias" con que cuentan estos agentes que han permanecido, de manera exitosa, desde antes de la aparición del hombre en la Tierra.

\section{REFERENCIAS}

AgERSO, Y., GUARDABASSI, L. 2005. Identification of Tet 39, a novel class of tetracycline resistance determinant in Acinetobacter spp. of environmental and clinical origin . J. Antimicrob. Chemother. 55:566-569.

AKIBA, T., Koyama, K., ISHIKI, Y., KimuRA, S., FUKUSHIMA, T. 1960. On the mechanism of the development of multiple-drugresistant clones of Shigella. Jpn. J. Microbiol. 4:219-227.

BROWN, M., ROBERTS, M. 1991. Tetracycline resistance determinants in streptococcal species isolated from the bovine mammary gland. Vet. Microb. 29:173-180.

BURDETT V. 1986. Streptococcal tetracycline resistance mediated at the level of protein synthesis. J. Bacteriol. 165:564-569.

BuRDETT, V. 1991. Purification and characterization of Tet(M), a protein that renders ribosomes resistant to tetracycline. J. Biol. Chem. 266:2872-2877.

Charpentier, E., Gerbaud, G., Courvalin, P. 1994. Presence of the Listeria tetracycline resistance gene tet $(\mathrm{S})$ in Enterococcus faecalis. Antimicrob. Agents Chemother. 38:2330-2335.

ChARPEnTIER, E., COURVAlin, P. 1999. Antibiotic resistance in Listeria spp. Antimicrob. Agents Chemother. 43:2103-2108.

CHOPRA, I., RoBERTS, M. 2001. Tetracycline Antibiotics: Mode of Action, cations, molecular Biology, and Epidemiology of Bacterial Resistance. Microbiol. Mol. Biol. Rev. 65:232-260.

Chung, W., Young, K. Leng Z., Roberts, M. C. 1999. Mobile elements carrying ermF and tetQ genes in Gram-positive and Gram-negative bacteria. J. Antimicrob. Chemother. 44:329-335.
Clermont, D., Chesneau, O., De Céspedes, G., Horaud, T. 1997. New tetracycline resistance determinants coding for ribosomal protection in streptococci and nucleotide sequence of tet(T) isolated from Streptococcus pyogenes A498. Antimicrob. Agents Chemother. 41:112-116.

Clewell, D., FlanNAGAN, S., JAWORSKI, D. 1995. Unconstrained bacterial promiscuity: the $\operatorname{Tn} 916-\operatorname{Tn} 1545$ family of conjugative transposons. Trends Microbiol. 3:229-236.

Connell, S., Tracz, D., Nierhaus, K., TAylor, D.E. 2003. Ribosomal Protection Proteins and Their Mechanism of Tetracycline Resistance Antimicrob Agents Chemother. 47:3675-3681.

DANCER, S., SHEARS, P., PlATT, D. 1997. Isolation and characterization of coliforms from glacial ice and water in Canada's High Arctic. J Appl Microbiol. 82:597-609.

Díaz-Torres, R., MCNab, D., Spratt, A., Villedieu, A., Hunt, N., Wilson, M., Mullany, P. 2003. Tetracycline Resistance Determinant from the Oral Metagenome Antimicrob. Agents Chemother 47:1430-1432.

Goldman, Ra., Hasan, T., Hall, CC., Strycharz, Wa., CoOPERMAN, BS. 1983. Photoincorporation of tetracycline into Escherichia coli ribosomes. Identification of the major proteins photolabeled by native tetracycline and tetracycline photoproducts and implications for the inhibitory action of tetracycline on protein synthesis. Biochemistry. 22:359-368.

Hughes, V., DATTA, N. 1983. Conjugative plasmids in bacteria of the 'pre-antibiotic' era. Nature. 21:725-726.

Jones, C., Osborne, D. Stanley, J. 1992. Enterobacterial tetracycline resistance in relation to plasmid incompatibility. Mol. Cell. Probes. 6:313-317.

Kehrenberg, C., Catry, B., Haesebrouck F., De Kruif, A., SCHWARZ, S. 2005. tet(L)-mediated tetracycline resistance in bovine Mannheimia and pasteurella isolates. J. Antimicrob Chemother. 56:403-406.

KIM, T.J., NA, Y.R., LEE, J. I. 2005. Investigation into the basis of chloramphenicol and tetracycline resistance in Staphylococcus intermedius isolates from cases of pyoderma in dogs. J. Vet. Med. 52:119-124.

LeVy, S. B., Mcmurry, L.M., Barbosa, T.M., Burdett, V., Courvalin, P., Hillen, W., Roberts, M.C., Rood, J., TAYLOR, D.E. 1999. Nomenclature for New Tetracycline Resistance Determinants . Antimicrob. Agents and Chemother. 43:1523-1524.

Lyras, D., Rood, J. 1996. Genetic organization and distribution of tetracycline resistance determinants in Clostridium perfringens. Antimicrob. Agents Chemother. 40:2500-2504.

MÉndeZ, B., TAChiBAnA, C., LeVy, S. 1980. Heterogeneity of tetracycline resistance determinants. Plasmid. 3:99-108.

Michalova, E., Novotna, P., Schlegelova, J. 2004. Tetracyclines in veterinary medicine and bacterial resistance to them. Vet. Med.-Czech. 49:79-100.

Miranda, C.D., Kerhenberg, C., Ulep, C., Schwarz, S., ROBERTS, M. 2003. Diversity of tetracycline resistance genes in bacteria from chilean salmon farms. Antimicrob. Agents Chemother. 47:883-888.

NONAKA, L., SUZUKI, S. 2002. New $\mathrm{Mg}^{2+}$-dependent oxytetracycline resistance determinant Tet 34 in Vibrio isolates from marine fish intestinal contents. Antimicrob. Agents Chemother. 46:1550-1552.

OEHLER, R., POLACEK, N., SteINER, G., BARTA., A. 1977. Interaction of tetracycline with RNA: photoincorporation into ribosomal RNA of Escherichia coli. Nucleic Acids Res. 25:1219-1224. 
OHMORI, H., KANEKO-OHDERA, M., NOMURA, T, HAWAI, T. 1991. Delta $\mathrm{pH}$-dependent accumulation of tetracycline in Escherichia coli Antimicrob Agents Chemother. 35:53-56.

OHNUKI, T., KaTOH, T., IMANAKA, T., AiBA, S. 1985. Molecular cloning of tetracycline resistance genes from Streptomyces rimosus in Streptomyces griseus and characterization of the cloned genes. J Bacteriol; 161:1010-1016.

Pang, Y., Brown, B.. Steingrube, V., Wallace, R., Roberts. M. C. 1994. Acquisition of gram-positive tetracycline resistance genes in Mycobacterium and Streptomyces species. Antimicrob. Agents Chemother. 38:1408-1412.

Perreten, V., Schwarz, F., Cresta, L., Boeglin, M., Dasen, G., TEUBER M. 1997. Antibiotic resistance spread in food. Nature. 389:801-802.

RoBerTS, M. 1994. Epidemiology of tetracycline-resistance determinants. Trends Microbiol. 2:353-357.

RoBERTS, M. 1996. Tetracycline resistant determinants: mechanisms of action, regulation of expression, genetic mobility and distribution. FEMS Microbiol Rev. 19:1-24.

ROBERTS M. 1997. Genetic mobility and distribution of tetracycline resistance determinants. Ciba Found Symp. 207:206-218.

ROBERTS, M. 2005. Update on acquired tetracycline resistance genes. FEMS Microbiol Letters. 245:195-203.

RoBerts, M., Moncla, B. J., Hillier, S. 1991. Characterization of unusual tetracycline-resistant gram-positive bacteria. Antimicrob. Agents Chemother. 35:2655-2657.

Ross, J.I., EADY, E., COVE, J., CUNLIFFE,W. 1998. 16S-rRNA mutation associated with tetracycline resistance in a gram- positive bacterium. Antimicrob. Agents Chemoter. 42:1702-1705.

Sahin, O., Plummer, P., Jordan, D., Sulaj, K., Pereira, S., RoBbe-Austerman, S., WANG, L., YAEgER, M., HofFMAN, L., ZHANG, Q. 2008. Emergence of a tetracycline-resistant Campylobacter jejuni clone associated with outbreaks of ovine abortion in the United States. J. Clin. Microbiol. 46:1663-1671.
SChNAPPINGER, D., HiLlen, W. 1996. Tetracyclines: antibiotic action, uptake, and resistance mechanism. Arch Microbiol. 165:359-369.

Scott, K., Melville, C., Barbosa, T., Flint, H. 2000. Occurrence of the new tetracycline resistance gene $\operatorname{tet}(\mathrm{W})$ in bacteria from the human gut. Antimicrob. Agents Chemother. 44:775-77.

Sougakoff, W., Papadopoulou, B., Nordmann, Courvalin, P. 1987. Nucleotide sequence and distribution of gene tet $O$ encoding tetracycline resistance in Campylobacter coli. FEMS Microbiol. Lett. 44:153-159.

SPEer, B., ShOEMAKER, N., SALYERS, A. 1992. Bacterial resistance to tetracycline: mechanisms, transfer, and clinical significance. Clin. Microbiol Rev. 5:387-399.

TAYLOR, D., CHAU, A. 1996. Tetracycline resistance mediated by ribosomal protection. Antimicrob. Agents Chemother. 40:1-5.

Tosini, F., Visca, P., Luzzi, I., Dionisi, A.M., Pezzella, C., PetrucCA, A., CARATtoli, A. 1998. Class 1 integron-borne multiple-antibiotic resistance carried by IncFI and IncL/M plasmids in Salmonella enterica serotype Typhimurium. Antimicrob. Agents Chemother., 42:3053-3058.

Villedieu, A., DíAZ-TORRES, M., HunT, N., MCNAB, R., SPRATT, D., Wilson, M., MullanY, B. 2003. Prevalence of Tetracycline Resistance Genes in Oral Bacteria Antimicrobial Agents and Chemotherapy. 47:878-882.

Yamaguchi, A., TAYlor, D., Chau, A. 1996. Tetracycline resistance mediated by ribosomal protection. Antimicrob. Agents Chemother. 40:1-5.

YAMAMOTO, K., SASAKI, Y., OGIKUBO, Y., NOGUChI, N., SASATSU, M., TAKAHASHI, T. 2001. Identification of the tetracycline resistance gene, tet(M), in Erysipelothrix rhusiopathiae. J. Vet. Med. 48:293-301.

Yang, W, Moore, I., Koteva, K., Bareich, D., Hughes, D., WRIGHT, G. 2004. TetX is a flavin-dependent monooxygenase conferring resistance to tetracycline antibiotics J. Biol. Chem. 279:52346-52352. 